\title{
Global Power Grids for Harnessing World Renewable Energy
}

\author{
Spyros Chatzivasileiadis $^{\mathrm{a}, 2, *}$, Damien Ernst ${ }^{\mathrm{b}, 1}$, Göran Andersson ${ }^{\mathrm{a}, 2}$ \\ ${ }^{a}$ Power Systems Laboratory, ETH Zurich, 8092 Zurich, Switzerland \\ ${ }^{b}$ Institut Montefiore, University of Liège, 4000 Liège, Belgium
}

\begin{abstract}
The Global Grid advocates the connection of all regional power systems into one electricity transmission system spanning the whole globe. Power systems are currently forming larger and larger interconnections. Environmental awareness and increased electricity consumption leads more investments towards renewable energy sources, abundant in remote locations (off-shore or in deserts). The Global Grid will facilitate the transmission of this "green" electricity to load centers, serving as backbone.

This chapter elaborates on the concept presenting four stages that could gradually lead to the development of a globally interconnected power network. Quantitative analyses are carried out for all stages, demonstrating that a Global Grid is both technically feasible and economically competitive. Real price data from Europe and the USA are used to identify the potential of intercontinental electricity trade, showing that substantial profits can be generated through such interconnections.
\end{abstract}

Keywords: global grid, electricity transmission network, global electrical network, renewable energy, wind power, solar power, Greenland, intercontinental electricity trade

\section{Introduction}

Increased environmental awareness has led to concrete actions in the energy sector in recent years. Examples are the European Commission's target of $20 \%$ participation of renewable energy sources (RES) in the EU energy mix by 2020 [1] and California's decision to increase renewable energy in the state's electricity mix to $33 \%$ of retail sales, again by 2020 [2]. At the same time, several studies have been carried out investigating the possibilities of a higher share of renewables in the energy supply system of the future. For instance, the German Energy Agency (DENA) assumes 39\% RES participation by 2020 [3], while a detailed study from the National Renewable Energy Laboratory suggests that meeting the US electricity demand in 2050 with $80 \%$ RES supply is a feasible option [4]. In [5], a 100\% renewable energy supply system in Europe with interconnections in North Africa and West Asia is discussed. More recently, Jacobson and Delucchi [6] investigated "the feasibility of providing worldwide energy for all purposes (electric power, transportation, heating/cooling,etc.) from wind, water, and sunlight". The authors made a detailed analysis and proposed a plan for implementation. They found that the barriers to the deployment of this plan are not technological or economic, but rather social and political.

All these studies suggest that the development of the electricity network will play a crucial role in the efficient inte-

\footnotetext{
${ }^{*}$ Corresponding author. Tel.:+41 446328990. Fax:+41 446321252.

Email addresses: spyros@eeh.ee.ethz.ch (Spyros Chatzivasileiadis), dernst@ulg.ac.be (Damien Ernst), andersson@eeh.ee.ethz.ch (Göran Andersson)

${ }^{1}$ Tel:+32 43669518; www.montefiore.ulg.ac.be/ ernst/

${ }^{2}$ www.eeh.ee.ethz.ch
}

gration of increasing shares of renewables. Two are the reasons most often mentioned. First, interconnecting RES increases the reliability in supply. Second, long transmission lines can help harvest renewable energy from remote locations with abundant potential and very low production costs. In order to exploit the benefits of such interconnections concrete actions have been taken, which will lead to the creation of regional Supergrids. EU Guidelines already encourage transmission projects such as the Baltic Ring [7]. Projects such as Medgrid 〈www.medgrid-psm.com〉, and OffshoreGrid 〈www . offshoregrid.eu $\rangle$ have been launched, in order to interconnect Mediterranean states with Europe and transfer renewable energy to the major load centers. At the same time, initiatives such as Gobitec 〈www.gobitec. org in Asia and Atlantic Wind Connection〈www.atlanticwindconnection.com〉 in the USA aim to interconnect the Asian power grids or transmit off-shore wind energy to the US East Coast.

In Ref. [8] we suggested the next natural step of the electricity network: the Global Grid. With growing electricity demand, the need for green energy resources will also increase. The electricity networks will expand in order to harvest the renewable potential abundant in remote locations, forming $\mathrm{Su}-$ pergrids of increasing size. The Global Grid aims at interconnecting the regional Supergrids into one global electricity network. High capacity long transmission lines will interconnect wind farms and solar power plants, supplying load centers with green power over long distances. Besides introducing the concept, in Ref. [8] we further highlighted the multiple opportunities emerging from it. We supported our analysis with studies on the economic feasibility of such a concept and we discussed possible investment mechanisms and operating schemes.

In this chapter, we introduce and elaborate on four possible 
stages that could gradually lead to the development of a globally interconnected power network. We extend our analysis with additional studies on the economic competitiveness of long transmission lines in different world regions and we show that substantial profits can arise from intercontinental electricity trade.

Section 2 introduces the four possible development stages followed by a brief illustration of the concept as we have envisioned it in Section 3. Sections 4-6 describe in detail all four development stages and provide examples with quantitative analyses for each stage. In Section 7 we briefly discuss the additional opportunities emerging from a Global Grid. We conclude this chapter with Section 8 .

\section{Stages towards a Global Power Grid}

We expect that three main reasons will act as the major incentives towards the creation of a globally interconnected network. First, the need to harvest remote renewable energy resources, either further off-shore or in deserts, will lead to continuously expanding regional Supergrids. Second, taking advantage of the shift in peak demand periods between continents, remote RES plants located in similar distances from two regions can connect and sell their power always at peak price. Third, the time zone diversity between the continents creates opportunities for electricity arbitrage, which can lead to profitable electricity trade. Based on these reasons, in this section we present four main stages we envision leading to the development of a Global Grid environment.

The main driving force behind a Global Grid will be the harvesting of remote renewable resources. In the search for green electricity, new sites will be exploited, even further from the load centers and the current power grids. Examples are deserts such as the Sahara or the Gobi for solar power plants; and on-shore or off-shore locations with high winds such as at the shores of Greenland, or in the Indian Ocean for wind farms. This constitutes the first stage towards a Global Grid. Our costbenefit analysis in this chapter will focus on the wind potential of such remote locations.

By building wind farms and solar parks in remote locations, a point will be reached, where a RES power plant will be in equal distance from two power systems on different continents. A wind farm in Greenland, for instance, would be a realistic example of such a situation. Our analysis in Ref. [8] showed that connecting such a wind farm to both Europe and North America is a profitable solution. In this second development stage of the Global Grid, remote RES power plants can take advantage of the time difference between the continents in order to sell their power always at peak prices. For example the wind farm in Greenland can sell its produced power $50 \%$ of the time during the peak demand in Europe and $50 \%$ of the time during the peak demand in North America. From there, an interconnected global power grid can start to form.

Having an electrical connection between two continents, opportunities for electricity trade emerge, signaling the progression to the third stage. Wind (and solar) production is intermittent, not utilizing the total cable capacity most of the time. In addition, peak demand between the continents is shifted in time, which leaves room for electricity arbitrage. Therefore, electricity can be bought at lower prices in one area and sold at higher prices during peak demand in other areas. In Section 5.2, we explore the electricity trade potential for the connection EuropeNorth America over Greenland, utilizing the remaining cable capacity.

As we will see in Section 5.2 the transmission corridor enabling electricity trade between the continents can result in substantial profits. Based on that, in the fourth stage of the development towards a Global Grid, direct interconnections between countries or continents can start to be built, independent from their connection to remote areas with high RES potential. Such an analysis for a cable between Europe and North America has already been carried out in Ref. [8], showing that except for the most expensive RES generators, it would be more economical for the US to import RES power from Europe than operate its own fossil-fuel power plants. Here, we extend this analysis considering real electricity prices in Germany and the USA and examining the amortization period of such an investment.

Introducing the four development stages helps create a path leading to a Global Grid environment. It does not imply, nevertheless, that global interconnections will move through the four stages in a sequential manner. For example, the direct interconnections in the fourth stage can directly occur after the first stage; or the second and third development stage can occur simultaneously, e.g. as we will see in Section 5 an off-shore wind farm can connect to both continents in order to sell at peak prices and, at the same time, benefit from the electricity trade.

\section{The Global Grid: An Illustration}

Before continuing our analysis, the current section is devoted to a brief description of the Global Grid as we envision it. This will hopefully produce a better understanding of this concept, first proposed in [8]. Figure 1 illustrates a possible global grid. We envision that the power supply of the Global Grid will depend on renewable energy sources. Large renewable potential exists in remote locations, such as in deserts or off-shore. Long HVDC lines will constitute the main arteries in a Global Grid environment, transmitting bulk quantities of power over long distances. HVDC lines are superior to AC technologies for long-distance transmission, as they exhibit lower losses, they provide active and reactive power support, and can connect nonsynchronous grids. Issues pertaining to the power generation and transmission of the Global Grid are described in more detail in Ref. [8].

\section{Harvesting RES from remote locations}

Tapping the renewable potential in Greenland, as mentioned in Section 2, would be a realistic example of how we could progress to global interconnections. Greenland has been selected in Ref. [8] as a representative example for three reasons. First, it has a significant wind and hydro potential [6],[9]. Second, it is close to Iceland; Ref. [10] has already shown that the Iceland-UK interconnection is a viable option, while 


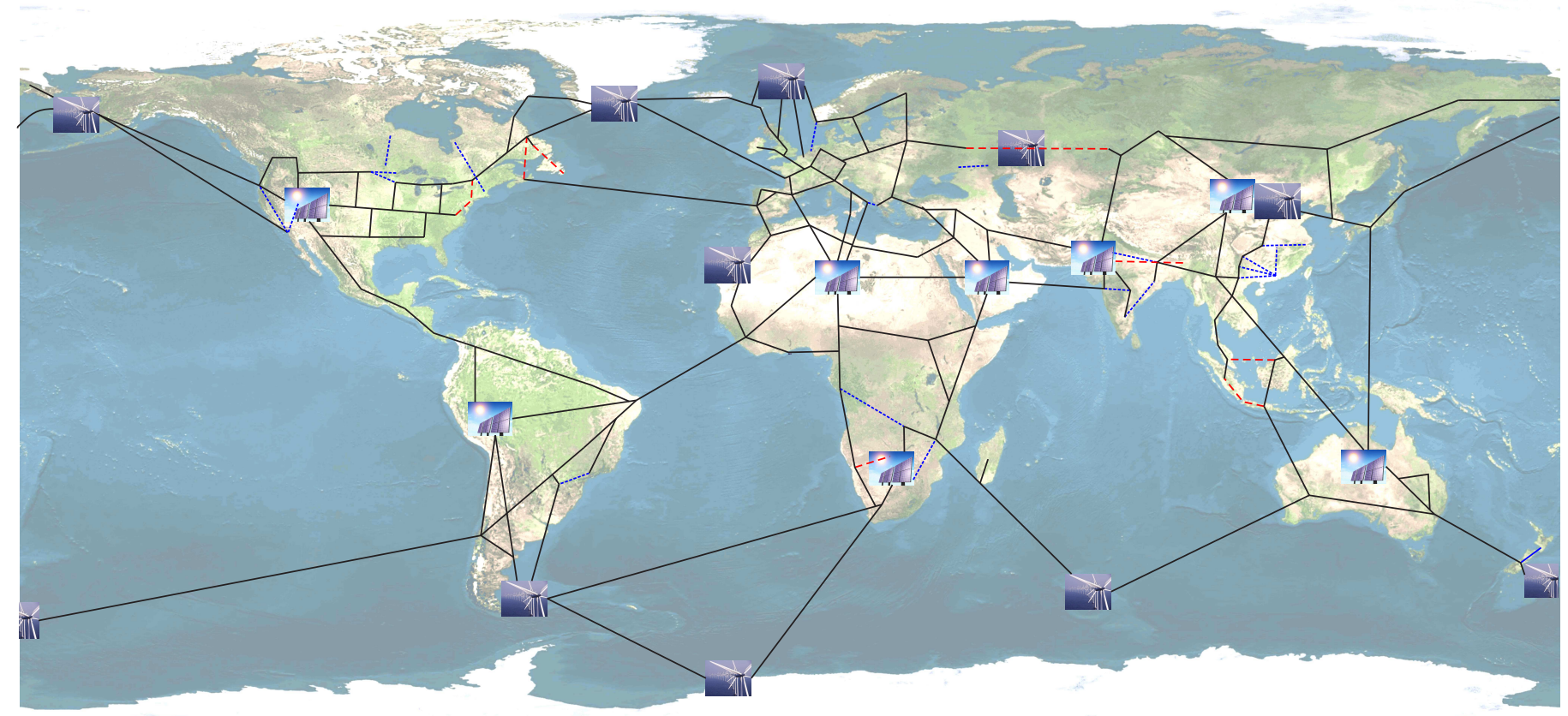

Figure 1: Illustration of a possible Global Grid. The blue dotted lines indicate the HVDC lines with a length over $500 \mathrm{~km}$, that are already in operation. The HVDC lines over $500 \mathrm{~km}$ currently in the building/planning phase are indicated in dashed red lines (the list with the illustrated HVDC lines is not exhaustive). The location of the RES power plants has been based on solar radiation maps, average wind speeds, and sea depths [8].

the two governments are currently discussing its possible realization [11]. Third, all interconnecting sections along this route have comparable lengths or sea depth to currently existing projects (see [8] for more details). Important is also that Greenland lies at equal distance from both Europe and North America. Later in this chapter we will extend our analysis on Greenland by exploring the possibilities for intercontinental trade.

In this section, we will move to the southern hemisphere, and we will study in more detail a wind farm on the Kerguelen islands. These are a group of islands located in the southern Indian Ocean and belonging to France. Their climate is similar to Iceland and Falkland islands, with an average temperature between $0{ }^{\circ} \mathrm{C}$ and $10{ }^{\circ} \mathrm{C}$ [12]. Kerguelen islands are characterized by the high continuous winds they receive, having an average speed of about $9.7 \mathrm{~m} / \mathrm{s}$. In about 312.9 days a year they experience wind gusts above $16 \mathrm{~m} / \mathrm{s}$, from which during 68.1 days the gusts exceed $28 \mathrm{~m} / \mathrm{s}$ in speed [13]. This is expected to have a substantial effect on the wind farm capacity factor, which is estimated at $60 \%-70 \% \%^{3}$.

Kerguelen islands are located approximately in equal distance between South Africa and Australia (about $4000 \mathrm{~km}$ to South Africa and about $4150 \mathrm{~km}$ to Western Australia). In order to account for the less favorable case, in this analysis we focus on the connection to South Africa assuming a cable length of $4150 \mathrm{~km}$. In this way, we can also gain insights for a possible

${ }^{3}$ Wind turbines are typically designed to reach their rated output power for wind speeds in the range between $14 \mathrm{~m} / \mathrm{s}$ and $25 \mathrm{~m} / \mathrm{s}$. Due to lack of additional wind data for Kerguelen islands, we assume that the wind turbines to be installed there will be designed such that the cut-out speed will be around $28 \mathrm{~m} / \mathrm{s}$. connection of the wind farm to Australia. Based on our calculations, detailed in Appendix A, the cable costs for a $4150 \mathrm{~km}$ route from Kerguelen islands would lie between 0.019 USD and 0.054 USD per delivered $\mathrm{kWh}$, dependent on the capacity factor of the wind farm. The cost for wind generation for 2020 and beyond has been projected in Ref. [14]. Onshore wind costs are estimated to start from below 0.04 USD per delivered $\mathrm{kWh}$, while offshore wind is projected to cost between $0.08-0.13$ USD per delivered kWh. All cost projections in Ref. [14] assumed a wind capacity factor of $40 \%$. Given the strong winds that Kerguelen islands receive, the wind capacity factor in that region is likely to be around $60 \%$. Furthermore, with an area of over $7,000 \mathrm{~km}^{2}$ and only 100 residents, there is plenty of space available for onshore wind farms. Due to economies of scale, the wind turbine production, transportation, and installation costs should also decrease. As a result, we expect that the wind production costs can start from as low as US\$0.02 per $\mathrm{kWh}$ for onshore and should not exceed US\$0.09 per $\mathrm{kWh}$ for offshore wind farms ${ }^{4}$.

Figure 2 presents the total cost per delivered $\mathrm{kWh}$, including both production and transmission to South Africa, plotted against varying wind production costs. In the graph we account for three different capacity factors of the wind farm, i.e. $40 \%$, $50 \%$, and $60 \%$, as well two cable cost projections: a high-cost and a low-cost. Each colored area represents a different capacity factor, with the lower costs per delivered $\mathrm{kWh}$ corresponding

\footnotetext{
${ }^{4}$ Kerguelen islands have resulted from volcanic formations. In such cases the sea depth increases quickly a few miles off the coast. Therefore, we expect that the majority of the wind farms installed on the Kerguelen islands would be onshore.
} 


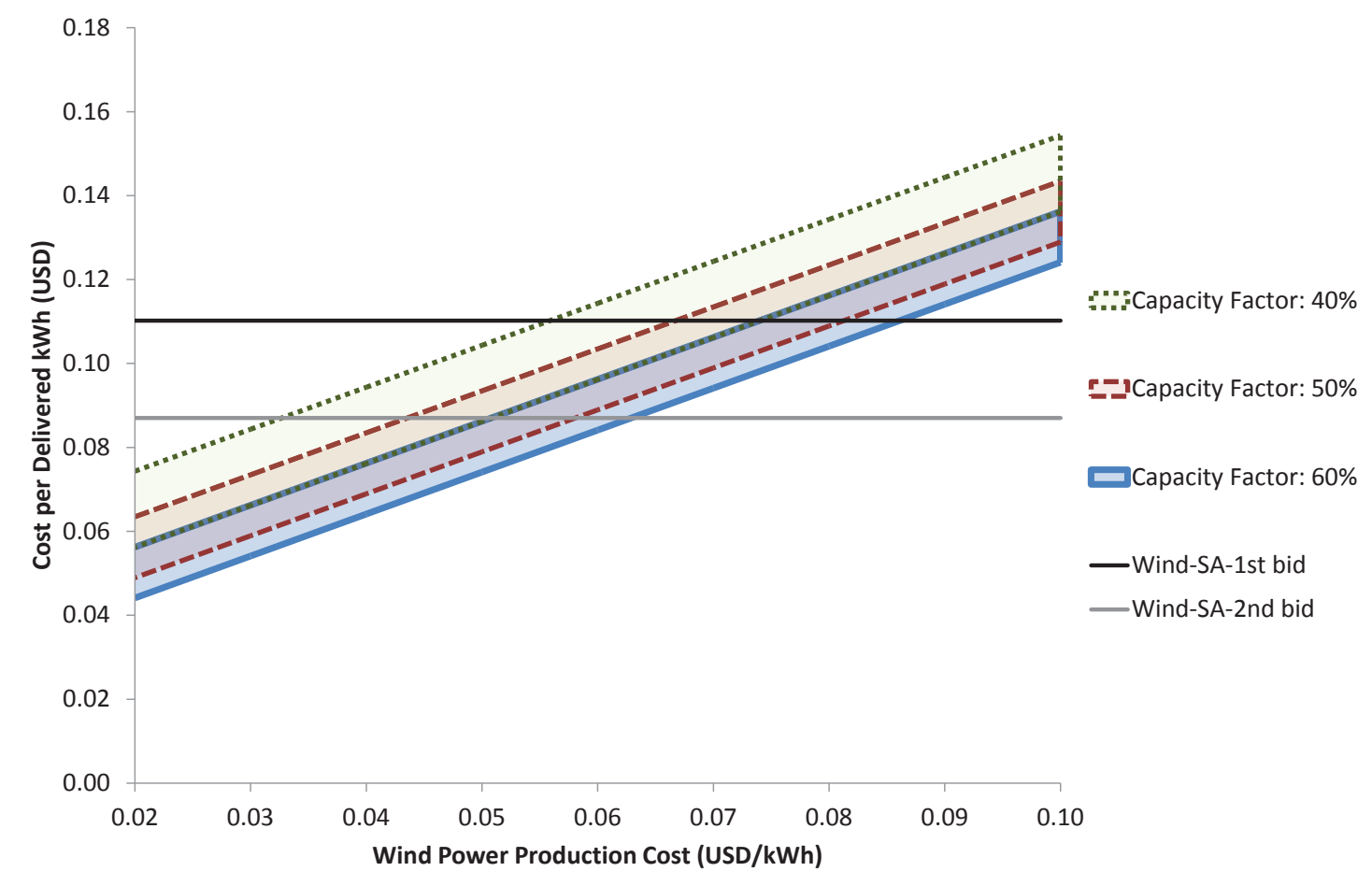

Figure 2: Wind farm on Kerguelen islands supplying South Africa. Total cost per delivered kWh (production \& transmission) for varying wind energy production costs, wind capacity factors, and cable costs. Each colored area corresponds to a different capacity factor and presents the cost spectrum depending on varying cost projections for the cable transmission and the wind power production. With Wind-SA-Bid are shown the constant prices per kWh that wind power producers in South Africa will receive, as determined in two rounds of a competitive bid process.

to a capacity factor of $60 \%$ and the higher costs corresponding to a capacity factor of $40 \%$. The bottom border of each colored area represents the low-cost cable projections, while the top border stands for the high-cost cable projections. As a result, the total wind production and transmission costs will lie somewhere within a colored area depending on the wind energy production costs and the cable costs. Beside the total costs for wind, in Fig. 2 we also plot the expected revenues per $\mathrm{kWh}$ for wind energy production, as these were determined from the South African government in 2011. In August 2011, South Africa launched a competitive bidding process for renewables. Two rounds of bids took place and the selected projects are expected to be commissioned by June 2014 (June 2015 for Concentrated Solar Power Plants) [15]. The average indexed bid prices for wind, expressed in USD, were $0.11 \mathrm{USD} / \mathrm{kWh}$ in the first round and $0.09 \mathrm{USD} / \mathrm{kWh}$ in the second round. These prices are also plotted as lines in Fig. 2.

As can be observed, for a wind capacity factor of $60 \%$, the wind farm on Kerguelen islands can compete with the local South African wind farms, if the wind energy production costs are below $0.085 \mathrm{USD} / \mathrm{kWh}$ considering the low-cost cable projection and revenues equivalent to the first round of bids in South Africa. In case of higher cable installation costs, the wind energy production costs should fall below $0.075 \mathrm{USD} / \mathrm{kWh}$. Given the high wind potential of this region, and the fact that the wind farm can be built on the island, the wind energy production costs, even under today's standards, are not expected to surpass these values e.g. 0.075-0.085 USD/kWh. With de- creasing capacity factors the cable costs per transmitted $\mathrm{kWh}$ increase. As a result, the wind energy production costs should also decrease so that the wind farm remains competitive with the South African wind farms. With a $40 \%$ capacity factor, as we observe in Fig. 2, the wind production costs should not exceed $0.033-0.055 \mathrm{USD} / \mathrm{kWh}$ in the worst case (depending on the revenues obtained through the first or second round of bids in South Africa). Taking into account that Ref. [14] projects the production costs for onshore wind farms to start below 0.040 USD/kWh, values such as $0.033 / \mathrm{kWh}$ can be highly probable by 2020 and beyond.

Being already connected to South Africa, the wind farm can also connect to Australia at a later stage, in order to take advantage of the time zone diversity and also facilitate electricity trade. As the distance from Kerguelen Islands to Australia is similar to the distance to South Africa, the cost projections, as shown in Fig. 2, are also valid for the cable connection to Australia.

\section{Interconnecting two continents over remote RES loca- tions}

In our analysis in Ref. [8], we assumed a $3 \mathrm{GW}$ wind farm off the east shores of Greenland is feasible and that some investors have decided to connect the wind farm with a $3 \mathrm{GW}$ line to Europe through Iceland and the Faroe Islands. We investigated whether a connection to North America would be profitable, taking into account two effects. First, due to the time zone dif- 
ference the wind farm will be able to sell its produced power always at peak prices, e.g., $50 \%$ of the time to Europe and $50 \%$ of the time to the USA. Second, by creating a link between Europe and the USA, over Greenland, opportunities for electricity trade between the continents emerge. As, the wind farm can produce power for a limited amount of time (we assume a capacity factor of $40 \%$ ), the cable capacity can be reserved for electricity trade for the remaining hours.

\subsection{Offering RES power at peak prices}

In our analysis in [8], we estimated that the cable can deliver about 20 TWh per year - taking into account the transmission losses. From this, about 10 TWh are allocated to the wind farm production. This means that for about $50 \%$ of the time the cable capacity is available for electricity trade.

By building the transmission route Greenland - USA, we found out that the costs per delivered $\mathrm{kWh}$ for the wind farm would increase by $21 \%-25 \%$, assuming production costs of $0.06 \mathrm{USD} / \mathrm{kWh}^{5}$. If off-peak prices are half of peak prices, the revenues will increase by $31 \%-33 \%$ which results in additional profits of $7 \%-12 \%$ for the wind farm, as shown in Table 1.

\subsection{Intercontinental electricity trade}

In this section, we focus on the electricity trade opportunities that emerge from the connection of the wind farm to both continents. Our analysis is based on real price data for the year 2012. We obtained the hourly spot prices from the European Power Exchange in Germany [16] and the PJM Interconnection in the USA [17]. Due to the time zone difference between the two continents, the two electricity markets experience at different time points their peak and lowest prices. Our analysis is detailed in Appendix B.2. We mainly examine two levels of utilization: $30 \%$ and $50 \%$. As already mentioned, $50 \%$ corresponds to the maximum utilization rate of the cable for electricity trade (the rest is used in order to transfer the power produced by the wind farm). We also investigate a lower utilization rate of $30 \%$, in order to account for a less favorable case (e.g. reduced availability of the cable or of excess renewable energy). Our investigations show that through the revenues generated from the electricity trade, the route between Greenland and North America can be amortized within $10-12$ years with a $50 \%$ utilization, and within 14-17 years if only $30 \%$ of the time the cable is used for electricity trade. Translating these results into profits, we find out that by exercising electricity trading during $30 \%$ of the time, the net profits ${ }^{6}$ will increase by $24 \%-27 \%$ in comparison with the case where the wind farm sells its wind power only to the UK and earns a profit of 0.06 USD for each delivered

\footnotetext{
${ }^{5}$ As already mentioned, Ref. [14] projects production costs of less than 0.04 USD/kWh for onshore and $0.08-0.13 \mathrm{USD} / \mathrm{kWh}$ for offshore wind farms by 2020. By assuming higher production costs, variations in transmission costs affect less the final cost per delivered kWh. In order to account for the less favorable case, we assumed lower production costs, allowing the transmission cost increase to play a more significant role in the final cost.

${ }^{6}$ The investment costs of the additional cable have been deducted from the electricity trade revenues.
}

$\mathrm{kWh}^{7}$. For exercising electricity trade during $50 \%$ of the time, the profits can increase up to $42 \%$. Table 1 summarizes our results.

Concluding, it seems that being connected to both continents would be a profitable solution for the wind farm in Greenland. In the last two sections, we investigated two possible sources of income created by building a transmission route from Europe to the USA over a wind farm in Greenland. First, selling the produced wind power always at peak prices, either in Europe or in the USA. Second, by trading electricity between the continents. Both options result independently to a profitable operation for the wind farm.

\section{Intercontinental interconnections by direct lines}

In Ref. [8], we carried out an analysis about the expected transmission costs per delivered $\mathrm{kWh}$. We estimated the cost of a $5500 \mathrm{~km}, 3 \mathrm{GW}$ submarine cable to be in the range between $€ 0.0166$ and $€ 0.0251$ per $\mathrm{kWh}$ delivered, and we found out that, except for the most expensive RES generators, it seems that it would be more economical for the US to import RES power from Europe than operate its own fossil-fuel power plants ${ }^{8}$.

Here, we extend our analysis in order to estimate if the cost for a long submarine cable could be amortized through the revenues arising by the electricity trade between the two continents. Again, we used the hourly spot prices for 2012 provided by PJM in the USA and EPEX in Germany [17], [16]. In our calculations we accounted for the transmission losses incurred by an $8000 \mathrm{~km}$ long corridor connecting the USA with Germany. We further assumed that before the realization of a direct submarine cable between the two continents, there will already exist long HVDC lines on land in both Europe and the USA. Therefore, we considered that the investment costs of this project correspond to the direct submarine cable between Europe and the USA, having a length of $5500 \mathrm{~km}$ and a capacity of $3 \mathrm{GW}$. In our analysis presented in Appendix B.1, we estimate that for an $80 \%$ utilization of the cable (i.e. the cable is used only $80 \%$ of the time), the amortization period ranges between 18 and 28 years. For the less favorable case where the cable utilization is $50 \%$, the amortization period increases to about 23-35 years, depending on the cost projections. Although such amortization periods might not be most attractive for private investors, these results highlight that from a social welfare point of view, such a cable is beneficial for the society.

\footnotetext{
${ }^{7}$ The profits from the intercontinental electricity trade are positive, i.e. the revenues surpass substantially the investment costs for the additional line in all cases. However, the increase in the final profit depends on the wind farm profits. Selling wind energy at higher prices to the UK results in lower variation of the total profit from the electricity trade revenues. In accordance with Section 5.1, where the production costs are assumed equal to $0.06 \mathrm{USD} / \mathrm{kWh}$, profits of 0.06 $\mathrm{USD} / \mathrm{kWh}$ imply a sell price of $0.12 \mathrm{USD} / \mathrm{kWh}$. Here, we account again for the less favorable case in our calculations, assuming that the wind farm generates substantial profits by selling the produced power at a price twice its marginal cost.

${ }^{8}$ The study is based on electricity generation from conventional sources estimated in Ref. [14] with fuel cost projections based on Ref. [18]. Unconventional sources of oil and gas such as oil sands and natural gas shales are also considered in the projections of Ref. [18].
} 
Table 1: Wind Farm in Greenland: Summary of the cost-benefit analysis results for connecting the wind farm to the USA

\begin{tabular}{|c|c|c|c|}
\hline \multicolumn{3}{|c|}{$\begin{array}{c}\text { Transmission Route: Europe - USA over Greenland } \\
\text { Total Cable Energy Capacity: } 20 \text { TWh }\end{array}$} \\
\hline & Wind Farm Production & \multicolumn{2}{c|}{ Electricity Trade } \\
\hline $\begin{array}{c}\text { Utilization } \\
(\% \text { of total time })\end{array}$ & $\begin{array}{c}\sim 0 \mathrm{TWh} \\
(40 \%)\end{array}$ & $\begin{array}{c}\sim 6 \mathrm{TWh} \\
(30 \%)\end{array}$ & $\begin{array}{c}\sim 10 \mathrm{TWh} \\
(50 \%)\end{array}$ \\
\hline $\begin{array}{c}\text { Profits } \\
\text { Increase }\end{array}$ & $7 \%-12 \%$ & $24 \%-27 \%$ & $39 \%-42 \%$ \\
\hline
\end{tabular}

a The wind farm is located in the middle of the path Europe-USA. As a result, it incurs only half of the transmission losses. That means that the same amount of power, e.g. $10 \mathrm{TWh}$, can be delivered in less time, resulting to a lower utilization factor of the transmission path.

\section{Discussion}

In the previous sections, we saw how intercontinental interconnections can take advantage of the time zone difference and smooth out electricity supply and demand. In this way, excess electricity production will not be irrevocably lost, but transmitted where it is most needed. Besides that, there are several additional opportunities that emerge from such a concept. In the following we provide a brief overview of them. For a more detailed analysis, referring to both the benefits and challenges that arise, the interested reader can refer to [8].

\subsection{Minimizing Power Reserves}

With the increasing penetration of RES, the necessary control reserve capacity is expected to increase [19]. Global interconnections can offer such services. Taking advantage of the timezone diversity, they can reserve control capacity in areas having lower electricity demand and offer it at locations which experience their peak demand at the same time. Offering an additional source of control power - supplementary to the control reserve options available in each control area - significant cost savings could emerge, as the building of additional "peaking" gas power plants for balancing renewable energy could be avoided. This has been investigated by the authors in [20] who compared the necessary conventional power plants in the presence or not of interconnecting lines between regions. Their results for both the European and a potential global grid showed that through interconnections the need for dispatchable conventional power plants could be reduced by two to eight times.

\subsection{Alleviating the Storage Problem}

Bulk quantities of storage will be necessary for absorbing non-transmissible power and relieving congestion (e.g., [3]). The HVDC links of the Global Grid have the potential to alleviate the storage problem in future power systems by absorbing excess power (i.e., with a low price) and injecting it into regions where it is needed more. In terms of efficiency, the losses of an Ultra High Voltage DC line (e.g., $\pm 800 \mathrm{kV}$ ) amount to about $3 \%$ for every $1000 \mathrm{~km}$ [21]. This would imply that a $6000 \mathrm{~km}$ HVDC line with the current technology has a better efficiency than pump-hydro or compressed-air energy storage.

\subsection{Additional Benefits}

Global Grid interconnections present additional opportunities that can prove beneficial to power systems. For example, they have the potential to reduce the volatility of electricity prices. They also allow the transmission of bulk power quantities with less power losses. Power system security can also be enhanced through such interconnections, in two ways. First, they provide additional pathways for the power to flow. Second, due to the HVDC technology, they offer independent active and reactive power control, and can act as a firewall between the systems they interconnect, not allowing disturbances to spread.

\section{Conclusions}

The Global Grid advocates the connection of all regional power systems into one electricity transmission system spanning the whole globe [8]. Power systems are currently forming larger and larger interconnections, while ongoing projects plan to supply, e.g., Europe with "green power" from the North Sea. Environmental awareness and increased electricity consumption will lead more investments towards renewable energy sources, abundant in remote locations (off-shore or in deserts). The Global Grid will facilitate the transmission of this "green" electricity to the load centers, serving as a backbone.

Having already introduced the concept in Ref. [8], this chapter presented four possible stages that could gradually lead to the development of a globally interconnected power network. Building long transmission lines in order to harvest remote renewable resources will be the main driving force in the first stage of the Global Grid development. From there, a point will be reached, where a RES power plant will be in equal distance from two power systems on different continents. Connecting the RES power plant to both continents in order to sell the produced power always at peak prices - taking advantage of the time zone diversity - will mark the second development stage of the Global Grid. As RES power plants usually have a capacity factor below $50 \%$, the remaining cable capacity can be used for intercontinental electricity trade. This signals the progression into the third development stage. As long as the profits from electricity trade are substantial, in the fourth development stage direct interconnections between countries or continents can start to be built. Introducing the four development stages 
helps to lay out a path leading towards a global grid environment. Nevertheless, the progression into these stages does not need to happen in a sequential manner, e.g. the fourth stage can follow directly the first, or the second and third stage can occur simultaneously.

Quantitative analyses for all four development stages have been provided in this chapter, showing that global interconnections can be both technically feasible and economically competitive. Exploring the possibility of a wind farm in Kerguelen Islands in the Indian Ocean, we showed that it can provide renewable energy to South Africa at a cost competitive to the local wind farms. At a later stage, this wind farm can connect to Australia, leading to intercontinental interconnections. We further estimated that connecting a wind farm in Greenland to both continents results in a profit increase of $7 \%-12 \%$. At the same time, the remaining cable capacity leaves room for intercontinental electricity trade. Based on real prices from Germany and PJM in the USA for 2012, we found out that electricity trade results to additional profits of $24 \%-42 \%$. We concluded our calculations by conducting a cost-benefit analysis for a direct submarine cable between Europe and the USA. The revenues from the intercontinental electricity trade, based again on real prices, result in an amortization period of 18-35 years for the cable investments, depending on the cable utilization factor. This highlights that from a social welfare point of view such a cable is beneficial for the society. Based on the results detailed in this chapter, additional studies are necessary on a technical, economical and societal level. The research community and the industry should also be encouraged to actively participate in order to identify the challenges and develop the solutions that could lead to a Global Grid.

\section{Appendix A. Cable Cost Projections}

In Ref. [8], we carried out a detailed analysis on the projected costs of a long HVDC submarine cable. In this work, we will adopt the same cost considerations. We will assume a $3000 \mathrm{MW}, \pm 800 \mathrm{kV}$ submarine cable. We selected the $\pm 800 \mathrm{kV}$ option, as we believe that for long-distance transmission, higher voltage levels will be adopted. We distinguish between two cost alternatives for the submarine cables. As a high-cost case, we assume a cost of $€ 1.8$ million/km for our $3000 \mathrm{MW}$ line, the same as what was suggested in [22] for a $5000 \mathrm{MW}$ sea cable. As a low-cost case, we assume the maximum cost of the completed HVDC projects (up to 2012 as presented in [8]). This is $€ 1.15$ million $/ \mathrm{km}$. The rest of the cost assumptions will be the same for both cases. Concerning the VSC converters, due to the higher voltage and the large capacity of the line, we assume the cost of each terminal converter to be $€ 300$ million. For additional details, the reader can refer to [8].

Kerguelen Islands. For the connection of Kerguelen Islands to South Africa we assume a $3000 \mathrm{MW}, \pm 800 \mathrm{kV}$ submarine cable with a length of $4150 \mathrm{~km}$. Based on the cost assumptions above and in Ref. [8], Table A.2 presents the transmission costs per delivered $\mathrm{kWh}$ for different wind farm capacity factors.
Table A.2: Kerguelen Islands rightarrow South Africa: Transmission Cost per delivered $\mathrm{kWh}$ (in USD).

\begin{tabular}{l|rrr}
\hline \multirow{2}{*}{ Cable Costs } & \multicolumn{3}{|c}{ Wind Farm Capacity Factor } \\
& $40 \%$ & $50 \%$ & $60 \%$ \\
\hline Low-Cost & 0.036 & 0.029 & 0.024 \\
High-Cost & 0.054 & 0.043 & 0.036 \\
\hline
\end{tabular}

Europe - North America over Greenland. For the route over Greenland, besides HVDC cables, the building of HVDC overhead lines will also be necessary. Thus, for HVDC overhead lines, we assume a cost of $€ 600$ million/1000 km, as also suggested by [23] and [14]. The detailed cost analysis can be found in Ref. [8].

Europe - North America through a direct submarine cable. We assume a $3000 \mathrm{MW}, \pm 800 \mathrm{kV}$ submarine cable with a length of $5500 \mathrm{~km}$. Note that the distance from Halifax, Canada to Oporto, Portugal is $4338 \mathrm{~km}$, while the distance from New York City to Oporto is $5334 \mathrm{~km}$.

\section{Appendix B. Electricity Trade between Europe and the USA - Detailed Analysis}

\section{Appendix B.1. Direct submarine cable}

In this section we detail the analysis we carried out in order to investigate the possibilities for electricity trade between Europe and the USA. Due to the time zone difference, the peak demand and, thus, the peak prices are shifted in time. Opportunities for electricity trade emerge. Our analysis is based on real hourly price data we obtained for Germany in Europe and the PJM interconnection in the USA for the year 2012. For Germany we took the hourly spot prices for 2012 from the European Power Exchange (EPEX) [16]. For PJM we took the real-time prices, and specifically the system energy price, i.e. the price component which is the same over the whole PJM area ignoring cost of congestion and losses [17]. We assume that the two power systems are connected through an $8000 \mathrm{~km}$ line, from which $5500 \mathrm{~km}$ correspond to the submarine cable between Oporto and New York, and the rest $2500 \mathrm{~km}$ correspond to an HVDC corridor between Oporto and Germany. We further assume that by the time the investment for the intercontinental cable takes place, there will already exist several HVDC interconnections within Europe as well as within the USA. These could be used for the power transfer between Oporto and Germany. Therefore, as investment costs we assume the cost of the submarine cable between Oporto and New York. Still, our calculations take into account the incurred losses along the total length of the corridor, i.e. the $8000 \mathrm{~km}$.

We assume a time difference of 6 hours between Germany and the US east coast where the PJM interconnection is located. The hourly prices in Euros are transformed to US dollars through average monthly exchange rates for $2012^{9}$. In our anal-

\footnotetext{
9 Source: http://www $\cdot x$-rates.com/average $/$ ? from=EUR\&to= USD\&amount $=1$ \&year $=2012$
} 
ysis we assume that the investment takes place in 2012 but the revenues are generated during the next 40 years, as this is the expected cable lifetime [24], [25], [10]. As data were available only for 2012, we assume that the prices over the next 40 years will be similar to 2012, considering a discount rate of $3 \%$, as suggested by [26, p. 9], and an inflation rate of $2.5 \%$. We distinguish between three different utilization rates for the cable: $30 \%, 50 \%$, and $80 \%$. This reflects the equivalent amount of hours per year during which the cable is used. For example, $30 \%$ utilization means that the cable transmits power up to its full capacity during $30 \%$ of the time. For a $30 \%$ utilization, electricity is traded when the price difference is above 35 USD, for $50 \%$ utilization the trade takes place for prices above 23 USD, and for $80 \%$ utilization the minimum price difference is 10 USD.

Table B. 3 presents the amortization period for the submarine cable. The cable generates revenues by buying electricity with a low marginal price in one continent and selling it at higher system marginal price to the other continent. As it can be observed, for a $50 \%$ and $80 \%$ utilization of the cable the payback time is less than the minimum cable lifetime, for both the highcost and the low-cost scenario. For a utilization of about $30 \%$, the cable is amortized only in the low-cost scenario. Here, it should be stressed that building a cable between the USA and Europe is not primarily a for-profit investment. The goal is to carry out an investment which will be beneficial for the social welfare. Thus, any amortization period which is less than the lifetime of the project is considered positive as it is expected to bring benefits to the society.

Table B.3: Amortization period (in years) for a high-cost and a low-cost projection of the cable.

\begin{tabular}{l|rrr}
\hline \multirow{2}{*}{ Cable Costs } & \multicolumn{3}{|c}{ Utilization } \\
& $30 \%$ & $50 \%$ & $80 \%$ \\
\hline Low-Cost & 31 & 23 & 18 \\
High-Cost & $>40$ & 35 & 28 \\
\hline
\end{tabular}

\section{Appendix B.2. Connecting Europe with the USA through the windfarm in Greenland}

The connection of the wind farm in Greenland to both continents facilitates electricity trade between Europe and the USA. In this paragraph we investigate if the costs for building the line between Greenland and the USA could be covered from the revenues generated from electricity trade. In our analysis for Greenland in Ref. [8], we calculated that $50 \%$ of the cable energy capacity over a year can be used for electricity trade. Two effects should be considered here. First, in reality the wind farm will often operate at capacities lower than its maximum. Therefore, on the one hand it can often occur that only a part of the transmission capacity will be available for electricity trade, but on the other hand this capacity will be available for longer than $50 \%$ of the time. Second, it may occur that during periods when there is substantial price difference between the two continents, the wind farm is producing power at the same time. As a result the transmission capacity cannot be used for profitable arbitrage. Due to these two effects, we assume that the "transmission capacity factor" for electricity trade will be about $30 \%$ while in the best case it will not exceed 50\%. Table B.4 presents the amortization period for three utilization levels of the cable: $30 \%, 50 \%$, and $80 \%$. (The $80 \%$ level is only presented for comparison reasons with Table B.3.) As we can observe, for a utilization of $30 \%$ to $50 \%$, the route Greenland-North America can be paid back within 10-17 years. It should be noted, that the payback period here does not take into account the additional profits the wind farm will have by selling its produced wind power always at peak prices. It is also interesting to point out that the route Germany-New York over Greenland has a similar distance to the route Germany-New York through a direct submarine cable between Oporto, in Portugal, and New York.

Table B.4: Amortization period (in years) for the transmission path Tasiilaq New York for a high-cost and a low-cost projection of the cable.

\begin{tabular}{l|rrr}
\hline \multirow{2}{*}{ Cable Costs } & \multicolumn{3}{|c}{ Utilization } \\
& $30 \%$ & $50 \%$ & $80 \%$ \\
\hline Low-Cost & 14 & 10 & 8 \\
High-Cost & 17 & 12 & 10 \\
\hline
\end{tabular}

\section{References}

[1] EC, . Impact assessment on the EU's objectives on climate change and renewable energy. European Commission; 2008.

[2] State of California, . Senate Bill X1-2 (sbx1 2). 2011.

[3] dena, . dena Grid Study II - Integration of Renewable Energy Sources in the German Power Supply System from 2015-2020 with an Outlook to 2025. German Energy Agency. Final Report; 2010.

[4] National Renewable Energy Laboratory, . Renewable energy futures study. Hand, M.M.; Baldwin, S.; DeMeo, E.; Reilly, J.M.; Mai, T.; Arent, D.; Porro, G.; Meshek, M.; Sandor, D. eds. 4 vols. NREL/TP-6A2052409. Golden, CO: National Renewable Energy Laboratory; 2012. [Online]: http://www.nrel.gov/analysis/re_futures/. Last accessed: 20/6/2012.

[5] Czisch, G.. Scenarios for a Future Electricity Supply: cost-optimized variations on supplying Europe and its neighbours with electricity from renewable energies. Institution of Engineering and Technology (IET); 2011.

[6] Jacobson, M.Z., Delucchi, M.A.. Providing all global energy with wind, water, and solar power, Part I: Technologies, energy resources, quantities and areas of infrastructure, and materials. Energy Policy 2011;39(3):1154 -1169 .

[7] Boute, A., Willems, P.. RUSTEC: Greening Europe's energy supply by developing Russia's renewable energy potential. Energy Policy 2012;51(0):618 - 629.

[8] Chatzivasileiadis, S., Ernst, D., Andersson, G.. The global grid. Renewable Energy 2013;57(0):372 - 383. URL http://www.sciencedirect.com/science/article/pii/ S0960148113000700.

[9] U.S. Energy Information Administration (EIA), . Greenland energy statistics. ca. 2012. [Online]: http://www.eia.gov/countries/ country-data. cfm?fips=GL. Last accessed: 20/6/2012.

[10] Hammons, T., Olsen, A., Kacejko, P., Leung, C.. Proposed Iceland/United Kingdom power link - An indepth analysis of issues and returns. IEEE Transactions on Energy Conversion 1993;8(3):566 - 575.

[11] The Guardian, . Iceland's volcanoes may power UK. 2012. [Online]: http://www.guardian.co.uk/environment/2012/apr/11/ iceland-volcano-green-power. Last accessed: 20/6/2012. 
[12] Wikipedia, . Kerguelen islands. Last accessed: 17/12/2013; 2013. [Online]: http://en.wikipedia.org/wiki/Kerguelen_Islands.

[13] Lafayne, C.. Updated information on france's antarctic and subantarctic "weather-forecasting" interests for the international antarctic weather forecasting handbook. Last accessed: 17/12/2013; 2008. [Online]: http://www.antarctica.ac.uk/met/momu/ International_Antarctic_Weather_Forecasting_Handbook/ update $\ \% 20$ France.php.

[14] Delucchi, M.A., Jacobson, M.Z.. Providing all global energy with wind, water, and solar power, Part II: Reliability, system and transmission costs, and policies. Energy Policy 2011;39(3):1170 - 1190.

[15] Wikipedia, . Energy in south africa. Last accessed: 17/12/2013; 2013. [Online]: http://en.wikipedia.org/wiki/Energy_in_ South_Africa.

[16] EPEX, . European Power Exchange. www. epexspot.com/en/; 2013.

[17] PJM, . PJM Interconnection LLC. www .pjm. com; 2013.

[18] U.S. Energy Information Administration (EIA), . Annual energy outlook. DOE/EIA-0383(2009), US Department of Energy, Washington, DC; 2009. [Online]: http://www.eia.gov/countries/country-data. cfm?fips=GL. Last accessed: 20/6/2012.

[19] Milligan, M., Donohoo, P., Lew, D., Ela, E., Kirby, B., Holttinen, H., et al. Operating Reserves and Wind Power Integration: An International Comparison. In: The 9th Annual International Workshop on Large-Scale Integration of Wind Power into Power Systems as well as on Transmission Networks for Offshore Wind Power Plants Conference. 2010,

[20] Aboumahboub, T., Schaber, K., Tzscheutschler, P., Hamacher, T.. Optimization of the utilization of renewable energy sources in the electricity sector. In: Proceedings of the 5th IASME / WSEAS International Conference on Energy \& Environment (EE'10). 2010,.

[21] Siemens, . Ultra HVDC transmission system. ca. 2011. [Online]: http: //www.energy.siemens.com/hq/en/power-transmission/ hvdc/hvdc-ultra/\#content=Benefits. Last accessed: 20/6/2012.

[22] DLR, . Trans-Mediterranean interconnection for concentrating solar power. German Aerospace Center, Institute of Technical Thermodynamics, Section Systems Analysis and Technology Assessment. Study commisioned by the Federal Ministry for the Environment, Nature Conservation and Nuclear Safety. Germany; 2006.

[23] Weigt, H., Jeske, T., Leuthold, F., von Hirschhausen, C.. "Take the long way down": Integration of large-scale North Sea wind using HVDC transmission. Energy Policy 2010;38(7):3164 - 3173.

[24] Skog, J.E.. HVDC Transmission and Life Expectancy. Memo StatnettTenneT; 2004. [Online]: http://www.tennet.org/english/ images/19-UK-B7-HVDC_Transmission_and_Lifetime_ Expectancy_tcm43-12302.pdf. Last accessed: 20/6/2012.

[25] Wikipedia, . NorGer. ca. 2011. [Online]: http://de.wikipedia.org/ wiki/NorGer. Last accessed: 20/6/2012.

[26] Short, W., Packey, D.J., Holt, T.. A manual for the economic evaluation of energy efficiency and renewable energy technologies. National Renewable Energy Laboratory; 1995. NREL/TP-462-5173. 